\title{
New Reports of Spiders in Three Mexican Ant-Acacias
}

\author{
Sandra Luz Gómez-Acevedo \\ Unidad de Morfología y Función, Facultad de Estudios Superiores Iztacala, Universidad Nacional Autónoma de México, \\ México City, México \\ Email: sanluza@unam.mx
}

How to cite this paper: Gómez-Acevedo, S.L. (2021) New Reports of Spiders in Three Mexican Ant-Acacias. Open Journal of Ecology, 11, 32-40.

https://doi.org/10.4236/oje.2021.111003

Received: November 16, 2020

Accepted: January 1, 2021

Published: January 4, 2021

Copyright (c) 2021 by author(s) and Scientific Research Publishing Inc. This work is licensed under the Creative Commons Attribution-NonCommercial International License (CC BY-NC 4.0). http://creativecommons.org/licenses/by-nc/4.0/ (c) (i) (\$) Open Access

\begin{abstract}
The richness of spider species on the foliage of Mexican ant-acacias in Los Tuxtlas (Veracruz), and Santiago Pinotepa Nacional (Oaxaca) was documented. A total of 11 species, grouped into five families were found; in Los Tuxtlas five species representing two families were identified, whereas in Santiago Pinotepa Nacional, the number of taxa was eight, belonging to five families. The richness of spiders in Santiago Pinotepa Nacional was higher than that found in Los Tuxtlas. In both locations Nephila clavipes Linnaeus and Eustala illicita O. Pickard-Cambridge, both from Araneidae, were found; these species had been previously reported as common inhabitants of Central American ant-acacias. The presence of E. illicita in Mexican myrmecophytic acacias was confirmed. A total of 10 species grouped into five families are reported for the first time inhabiting Mexican ant-acacias, increasing the richness of spider interactions documented in Mexico. This study showed that the occurrence of spiders in the Vachellia-Pseudomyrmex mutualism system has been overlooked and is likely more common than what has been reported until now. This opens an opportunity for the study of the evolution of spider-ant-plant interactions.
\end{abstract}

\section{Keywords}

Myrmecophily, Mutualism, Plant-Animal Interaction

\section{Introduction}

The mutualistic relationship between myrmecophytic acacias and their ant inhabitants is one of the best-known symbioses so far and is frequently cited as an example of coevolution since Janzen's [1] work. There are 15 species of Neotropical ant-acacias, each belonging to the formerly Acacia genus, now Vachellia 
[2] [3] and can be identified by the establishment and maintenance of an obligatory association with one of ten ant species from the Pseudomyrmex ferrugineus group. The collective distribution of both species covers the area between central Mexico and northwestern Colombia [4] [5] [6].

The origin of this relationship dates back to the transition between the end of the Miocene ( $5.44 \pm 1.93 \mathrm{Ma}$ ) and the beginning of the Pliocene $(4.58 \pm 0.82 \mathrm{Ma})$ in the Mesoamerican region, with an eventual diversification of both groups in Mexico [6] [7]. As a result of this evolutionary interaction, a high degree of morphological specialization in both members of the interaction is produced. The ant-acacias provide food (Beltian bodies and extrafloral nectaries) and permanent shelter and nesting space (domatia) to their resident ant partners, who in turn remove herbivorous insects and fungus spores from their host's leaves [1] [5]. The Beltian bodies are made up of lipids ( $1 \%-10 \%$ of dry mass), proteins and free amino acids ( $8 \%-14 \%$ of dry mass), carbohydrates $(3 \%-11 \%$ of dry mass) and water ( $18 \%-24 \%$ of total mass) and are used as a food source for the larvae of the mutualistic ants [8].

Due to the food rewards offered, these relationships are commonly exploited by other species, who collect the rewards provided by the plants but do not protect them against herbivores or competitors [9] [10]. Parasitic ants have been reported to take advantage of this mutualism [10] [11], and even the spider Bagheera kiplingi Peckham and Peckham (Salticidae) has been observed to feed on both Beltian bodies and extrafloral nectaries of two ant-acacias in Mexico and Costa Rica [12]. This spider inhabits myrmecophytic acacias almost exclusively, and hundreds of them can live on a single plant; they construct their nests on the tips of the older leaves, hence avoiding the patrolling of the mutualistic ants. In Mexico, B. kiplingi inhabits Vachellia collinsii and the Beltian bodies make up $91 \%$ of its diet, while in Costa Rica it lives in V. collinsii and V. cornigera, where Beltian bodies represent $60 \%$ of its diet, which is complemented with extrafloral nectar from the acacia, ant larvae, small flies, and rarely, small spiders [12].

To date only two more cases of spiders inhabiting neotropical ant-acacias have been documented. In Panama Eustala illicita O. Pickard-Cambridge and E. oblonga Chickering, both belonging to the Araneidae family, were found on V.collinsii and $V$. melanoceras respectively [13] [14]. Styrsky [15] mentioned that $E$. oblonga does not feed on the rewards provided by the plant, but rather exploit the enemy-free space provided by the patrolling ants and occupies the ant-acacias to construct a web and capture insects flying through the acacia foliage and probably insects that perch on it. Some authors consider these spiders myrmecophilous, that is, living in tight association with ants [14] [15]. It should be noted that myrmecophily has only been documented in 40 spider species, grouped in 13 families [16] [17].

The neotropical Vachellia-Pseudomyrmex mutualism has been traditionally studied regarding the ants, the ant-acacias, or both, emphasizing aspects of their life cycle, ecology and evolutionary history [1] [4] [7] [8] [9] [10] [11] [18]. However, despite the fact that Mexico has the largest number of ant-acacias [19], 
little is currently known about other organisms that could be present in this system, particularly spiders. In this sense, it is important to highlight that the biodiversity of a region is a function of not only the number of species, but also the richness of interactions among them.

This study was carried out with the aim of documenting the richness of spider species in ant-acacias from two populations in Oaxaca and Veracruz, two Mexican states with geographical separation by two major mountain ranges, where there is high biological diversity per se. This will in turn allow for comparisons between the two localities and provide information regarding the similarity of spider richness between the species of ant-acacias of each locality and between localities. The questions that led to this study were: 1 ) will ant-acacias present spiders on their foliage? and if this is the case, 2) will the same species of spiders be found in two geographically different sites?, 3) will the same species of spiders be found in different species of ant-acacias in the same locality? and 4) does the presence of spiders on the ant-acacias depends on which mutualistic ant is present?

\section{Materials and Methods}

The study was carried out in "Los Tuxtlas" (LT) Tropical Biology Station in the state of Veracruz and in Santiago Pinotepa Nacional (SPN), Oaxaca. LT region is located at $95^{\circ} 04^{\prime}-95^{\circ} 09^{\prime}$ West Longitude and $18^{\circ} 34^{\prime}-18^{\circ} 36^{\prime}$ North Latitude, while SPN is at $98^{\circ} 03^{\prime}$ West Longitude and $16^{\circ} 20^{\prime}$ North Latitude. LT characteristic vegetation is mainly evergreen lowland rainforest and is currently a relic of what the Tuxtlas area was; it is surrounded by open sites (grasslands and paddocks) distributed throughout the region due to human activities such as agriculture and livestock grazing. Two ant-acacias are present in this region: Vachellia cornigera and $V$. mayana. The first grows particularly in open sites, while the second is only found in the preserved forest of LT. The mutualistic ant species is Pseudomyrmex ferrugineus $\mathrm{F}$. Smith in both species. In SPN, nearly half is primary vegetation that includes rainforest, and to a lesser extent patch of sand dunes, mangroves, savannas and cattail wetlands. The remaining secondary vegetation is a result of agriculture and expansion of urban areas. This region is particularly inhabited by ant-acacias that grow in disturbed sites, such as $V$. cornigera and $V$. hindsii, the mutualistic ant species present in both ant-acacias is Pseudomyrmex peperi Forel.

Field work took place during the months of June/November (LT) and July/December (SPN) in 2014. The following individuals of ant-acacia were located at the sampling sites: $V$. cornigera (22) and $V$. mayana (5) in LT, and V. cornigera (14) and $V$. hindsii (6) in SPN. Each plant was georeferenced and afterwards, observations were made. We assured that no sudden movements were made, or foliage was touched, in order to prevent spiders from escaping. Even so, on few occasions some spiders quickly escaped from plants when they noticed human presence. Each plant was observed for about 15 minutes in search of spiders. Not all ant-acacias had spiders, and when they were found behavioral observations were carried out on their diurnal activities by approximately ten 
minutes. Behaviors were classified according to the four types proposed by García and Styrsky [14]: 1) crouching: the spider rested with its body pressed against the plant surface and its legs folded close to its body, 2) standing: the spider was motionless but with its body elevated, legs outstretched, and supported by the plant surface, 3) crawling: the spider was walking or running across the plant surface, and 4) on webs or web strands: the spider was not in contact with the plant surface. After the observations, the specimens were captured manually and only during the day (from 9:00 to 13:00), using pruners, paintbrushes and entomological forceps. Specimens were preserved in $70 \%$ ethanol for later identification and curation and were then incorporated as part of the Arachnid National Collection (CNAN) at the Institute of Biology of the National Autonomous University of Mexico.

\section{Results}

\subsection{Richness between Localities}

A total of 11 spider species from five families (Araneidae -the most abundant-, Pisauridae, Salticidae, Sparassidae and Tetragnathidae) were collected. In LT, five species were recorded, three of which were only found in this site. In SPN eight species were found, of which six were present only in this region (Table 1, Figures 1(A)-(F)). In both localities, Eustala illicita (Figure 1(D)) and Nephila clavipes Linnaeus, 1767 (Figure 1(A) and Figure 1(B)) were found. It is important to mention that E. illicita was only captured on $V$. cornigera and not on $V$. mayana in LT. Similarly, $N$. clavipes was only recorded on $V$. hindsii but not on $V$. cornigera in SPN (Table 1), even though both acacias were very close to each other in the sampling zone.

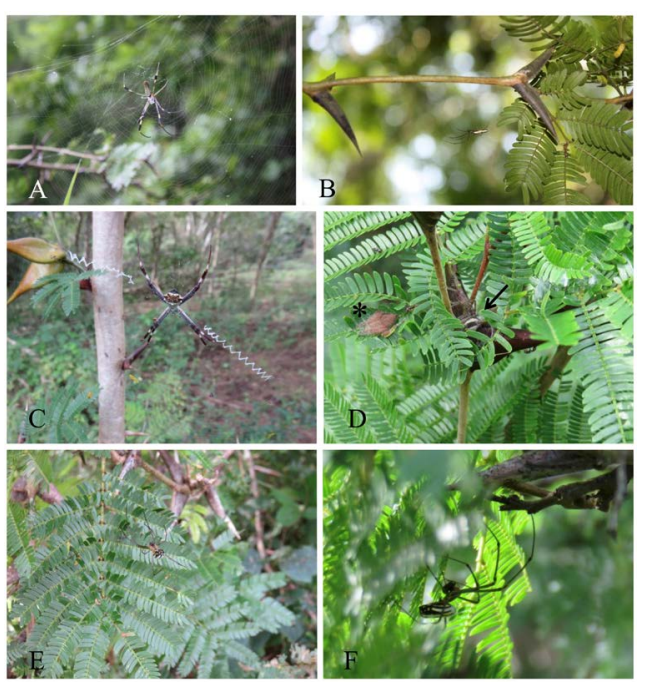

Figure 1. Spiders found on ant-acacias in Los Tuxtlas ((A) and (B)) and in Santiago Pinotepa Nacional ((C)-(F)), Mexico. (A) Nephila clavipes on Vachellia cornigera; (B) Nephila clavipes on V. mayana; (C) Argiope argentata on V. hindsii; (D) Eustala illicita (asterisk) and Tinus sp. (arrow). Some patrolling ants can be seen; (E) and (F) Leucage cf. mariana on $V$. hindsii. 
Table 1. List of the spider species found on the foliage of the Mexican ant-acacias. Types of behavior sensu García \& Styrsky [14]: 1) crouching, 2) standing, and 4) on webs or web strands.

\begin{tabular}{|c|c|c|c|c|c|}
\hline \multirow{2}{*}{ Spider species } & \multirow{2}{*}{$\begin{array}{c}\text { Spider } \\
\text { behavior }\end{array}$} & \multicolumn{2}{|c|}{ Los Tuxtlas } & \multicolumn{2}{|c|}{ Santiago Pinotepa Nacional } \\
\hline & & V. cornigera & $V$. mayana & $V$. cornigera & V. hindsii \\
\hline \multicolumn{6}{|l|}{ Araneidae } \\
\hline Argiope argentata & 4 & & & & - \\
\hline Eustala illicita & 1 & • & & • & • \\
\hline Eustala sp. & 4 & & & • & \\
\hline Larinia directa & 4 & - & & & \\
\hline Nephila clavipes & 4 & - & - & & - \\
\hline Verrucosa arenata & 4 & $\bullet$ & $\bullet$ & & \\
\hline \multicolumn{6}{|l|}{ Pisauridae } \\
\hline Tinus sp. & 1 & & & - & - \\
\hline \multicolumn{6}{|l|}{ Salticidae } \\
\hline Metaphidippus sp. & 2 & - & & & \\
\hline Plexippus sp. & 2 & & & - & \\
\hline \multicolumn{6}{|l|}{ Sparassidae } \\
\hline Curicaberis sp. & 2 & & & - & \\
\hline \multicolumn{6}{|l|}{ Tetragnathidae } \\
\hline Leucauge cf. mariana & 4 & & & $\bullet$ & \\
\hline
\end{tabular}

\subsection{Richness between Ant-Acacia Species}

The highest spider richness was present in Vachellia cornigera foliage, with five species within three families in LT and six species within five families in SPN; the lowest richness was on $V$. mayana with just two species into two families. Four spider species, belonging to three families (Table 1) were collected on $V$. hindsii. It should be highlighted that E. illicita and Tinus sp. were found very near to each other on a single $A$. hindsii individual; E. illicita on the leaflets, and Tinus sp. on a domatium (Figure 1(D)).

\subsection{Spider Behavior}

Only immobility behaviors (types 1, 2 and 4) were observed in spiders of both LT and SPN (Table 1). Of the six species from the family Araneidae, five were observed on web strands (type 4), and Eustala illicita in a crouching position (type 1) (Figures 1(A)-(D)). Species from the family Pisauridae were also observed performing a behavior type 1 (Figure $1(D)$ ). All the species from the Salticidae and Sparassidae families were found in a standing behavior (type 2), and the species from the family Tetragnathidae on a web strand, that is, not in contact with the plant surface, which corresponds to the behavior type 4 (Figure 1(E) and Figure 1(F)). 


\section{Discussion}

The neotropical Vachellia-Pseudomyrmex system is considered a highly stable obligate mutualism, in which their mutualistic ants actively patrol the plants, chasing away and eliminating any other organism [1] [4]. However, during the fieldwork for this study, a variety of insects (flies, wasps, bedbugs and ladybugs; unpublished data) and spiders were occasionally noticed and recorded. The spiders seemed not to be bothered nor chased away by the resident ants, even when they were very close to them or on domatia.

Styrsky [15] showed that despite the effectiveness of the patrol activities of the mutualistic ants (Pseudomyrmex satanicus Wheeler) on the Panamanian myrmecophytic Vachellia melanoceras, the spider Eustala oblonga is abundant on adult plants, and hundreds of individuals, both adults and juveniles, can coexist. Moreover, Meehan et al. ([12], supp. mat.) mentioned that in Mexico (Quintana Roo), a single $V$. collinsii individual may host more than 200 spiders, while in Costa Rica the individuals of $V$. collinsii and V. cornigera have barely a few organisms of Bagheera kiplingii on their foliage. Unlike in Quintana Roo and Panama, but similar to Costa Rica, in both areas of this study few individuals of each spider taxon were found on each acacia individual, only about five or fewer per day.

García and Styrsky [14] defined four types of behavior based on the spiders that inhabit the Panamanian myrmecophytic V. melanoceras. Of all these behaviors, only one of them involves the individuals being in movement (type 3) and the remaining three imply different versions of immobility (types 1,2 and 4). In the present study, all the spiders behaved in some category of immobility. This work highlights the importance of myrmecophytic acacias, providing the spiders with important sites for resting and feeding. It is even appropriate to point out that spider richness was higher in ant-acacias located in the paddocks of both study areas ( $V$. cornigera and $V$. hindsii), than on $V$. mayana, which inhabits only the preserved original vegetation area of LT, suggesting that spiders could prefer plants located in open spaces as habitats. Several authors have shown that spiders are highly selective of both their microhabitat and their foraging sites to maximize their survival and reproductive success [20] [21].

Previous works where the presence of spiders in the Vachellia-Pseudomyrmex system is documented [12] [13] [14] [15] do not mention if these taxa show any preference for inhabiting a particular ant-acacia. On the contrary, the results found in this study suggest a tendency for spiders to occupy $V$. cornigera, the species on which spider diversity was highest in both study areas, regardless of which mutualistic ant species is present. That is, Pseudomyrmex ferrugineus inhabited the domatia of $V$. cornigera and $V$. mayana in LT, while in SPN, the resident ant of $V$. cornigera and $V$. hindsii is $P$. peperi; so the choice of a myrmecophytic plant over another is not a function of the patrolling activities of the resident ant, but rather a function of the host traits. The fact that higher spider diversity was found on $V$. cornigera was surprising, since it is considered a "high-reward" host for its resident ants, and thus displays a greater defense and 
protection against herbivorous and exploiters compared to $V$. hindsii, which offers a "low-reward" and therefore receives less care and defense from its ants [11].

\section{Conclusions}

The presence of 11 species of spiders (10 new records) on the foliage of three Mexican ant-acacias suggests that these taxa in the Vachellia-Pseudomyrmex system are more common than previously thought and represent an opportunity for the study of the evolution of biological relationships in Mexico. All of these spiders were found in some types of immobility (mainly in their webs), behaviors that probably do not involve any alarm signals for mutualistic ants. In addition, the fact that the largest number of spiders found in this study belongs to the Araneidae family suggests that either this spider family is more tolerated by mutualistic ants, or that it has evolved highly efficient strategies to avoid being detected by them, which may tend toward a more stable evolutionary relationship.

Also, it would be useful to carry out future studies on the structural, morphological and/or physiological traits present in $V$. cornigera that could make it a more attractive or favorable acacia for spiders, as well as the mechanisms that spiders (mainly the Araneidae family) may employ to avoid or coexist with the mutualistic ants. Moreover, this study lays foundations for complementary studies regarding the spider richness over the whole range of the distribution of both $V$. cornigera and $V$. hindsii, two widely represented species in Mexico. In this sense, it is important to take into account that biological interactions have become an essential component in the evolution of the world's biodiversity and that they are inherently a part of a continuous gradient of interrelationships, in which the outcome of an interaction could change both spatially and temporally as a result of the presence or absence of any of the interacting species, in accordance with the geographic mosaic theory of coevolution [22] [23].

\section{Acknowledgements}

This work was supported by UNAM-PAPIIT (IA203515) and PAPCA (FESI-DIP-PAPCA-2014-38). The author expresses her gratitude to the Biol. Rosamond Coates and the MSc. Álvaro Campos (Tropical Biology Station "Los Tuxtlas") and the Ávila family (Santiago Pinotepa Nacional, Oaxaca) for the facilities granted during the recollection of the material. The author thanks Javier Martínez and Orlando Trujillo for field support; Dariana Guerrero-Fuentes, Daniela Candia-Ramírez and César Durán from the Arachnid National Collection (CNAN), for their help in the identification of some spiders; and Erika Aguirre-Planter for English support. The author states that there is no conflict of interest. This paper was written during a sabbatical leave of SLG-A.

\section{Conflicts of Interest}

The author declares no conflicts of interest regarding the publication of this paper. 


\section{References}

[1] Janzen, D.H. (1966) Coevolution of Mutualism between Ants and Acacias in Central America. Evolution, 20, 249-275. https://doi.org/10.1111/j.1558-5646.1966.tb03364.x

[2] Murphy, D.J. (2008) A Review of the Classification of Acacia (Leguminosae, Mimosoideae). Muelleria, 26, 10-26.

[3] Miller, J.T. and Seigler, D.S. (2012) Evolutionary and Taxonomic Relationships of Acacia s.l. (Leguminosae: Mimosoideae). Australian Systematic Botany, 25, 217-224. https://doi.org/10.1071/SB11042

[4] Janzen, D.H. (1974) Swollen-Thorn Acacias of Central America. Smithsonian Contribution to Botany No. 13, 1-131. https://doi.org/10.5962/bhl.title.123341

[5] Ward, P.S. (1993) Systematic Studies on Pseudomyrmex Acacia-Ants (Hymenoptera: Formicidae: Pseudoyrmecinae). Journal of Hymenoptera Research, 2, 117-168.

[6] Ward, P.S. and Branstetter, M.G. (2017) The Acacia Ants Revisited: Convergent Evolution and Biogeographic Context in an Iconic Ant/Plant Mutualism. Proceedings of the Royal Society B, 284, Article ID: 20162569.

https://doi.org/10.1098/rspb.2016.2569

[7] Gómez-Acevedo, S., Rico-Arce, L., Delgado-Salinas, A., Magallón, S. and Eguiarte, L.E. (2010) Neotropical Mutualism Acacia-Pseudomyrmex: Phylogeny and Divergence Times. Molecular Phylogenetics and Evolution, 56, 393-408. https://doi.org/10.1016/j.ympev.2010.03.018

[8] Heil, M., Baumann, B., Krüger, R. and Linsenmair, E. (2004) Main Nutrient Compounds in Food Bodies of Mexican Acacia Ant-Plants. Chemoecology, 14, 45-52. https://doi.org/10.1007/s00049-003-0257-x

[9] Raine, N.E., Gammans, N., MacFadyen, I.J., Scrivner, G.K. and Stone, G.N. (2004) Guards and Thieves: Antagonistic Interactions between Two Ant Species Coexisting on the Same Ant-Plant. Ecological Entomology, 29, 345-352.

https://doi.org/10.1111/j.0307-6946.2004.00608.x

[10] Clement, L.W., Köppen, S.C., Brand, W.A. and Heil, M. (2008) Strategies of a Parasite of the Ant-Acacia Mutualism. Behavioral Ecology and Sociobiology, 26, 953-962.

https://doi.org/10.1007/s00265-007-0520-1

[11] Heil, M., González-Teuber, M., Clement, L.S., Kautz, S., Verhaagh, M. and Silva, B.J.C. (2009) Divergent Investment Strategies of Acacia Myrmecophytes and the Coexistence of Mutualists and Exploiters. Proceedings of the National Academy of Sciences of the United States of America, 106, 18091-18096.

https://doi.org/10.1073/pnas.0904304106

[12] Meehan, C.J., Olson, E.J., Reudink, M.W., Kyser, T.K. and Curry, R.L. (2009) Herbivory in a Spider through Exploitation of an Ant-Plant Mutualism. Current Biology, 19, R892-R893. https://doi.org/10.1016/j.cub.2009.08.049

[13] Hesselberg, T. and Triana, E. (2010) The Web of the Acacia Orb-Spider Eustala illicita (Araneae: Araneidae) with Notes on Its Natural History. Journal of Arachnology, 38, 21-26. https://doi.org/10.1636/HI09-59.1

[14] García, L.C. and Styrsky, J.D. (2013) An Orb-Weaver Spider Eludes Plant-Defending Acacia Ants by Hiding in Plain Sight. Ecological Entomology, 38, 230-237. https://doi.org/10.1111/een.12012

[15] Styrsky, J.D. (2014) An Orb-Weaver Spider Exploits an Ant-Acacia Mutualism for Enemy-Free Space. Ecology and Evolution, 4, 276-283.

https://doi.org/10.1002/ece3.930 
[16] Cushing, P.E. (1997) Myrmecomorphy and Myrmecophily in Spiders: A Review. Florida Entomologist, 80, 165-193. https://doi.org/10.2307/3495552

[17] Cushing, P.E. (2012) Spider-Ant Associations: An Updated Review of Myrmecomorphy, Myrmecophily, and Myrmecophagy in Spiders. Psyche: A Journal of Entomology, 2012, Article ID: 151989. https://doi.org/10.1155/2012/151989

[18] Gómez-Acevedo, S.L., Rico-Arce, L., Delgado-Salinas, A., Magallón, S. and Eguiarte-Fruns, L. (2015) Análisis molecular del género Acacia (Leguminosae, Mimosoideae), con énfasis en el grupo mirmecófilo. In: Fortunato, R., Ed., $V$ Conferencia Internacional de Leguminosas, CICCUS Buenos Aires, 201-223.

[19] Rico-Arce, M.L. (2007) A Checklist and Synopsis of American Species of Acacia (Leguminosae: Mimosoideae). CONABIO, México.

[20] Romero, G.Q. and Vasconcellos-Neto, J. (2004) Spatial Distribution Patterns of Jumping Spiders Associated with Terrestrial Bromeliads. Biotropica, 36, 596-601. https://doi.org/10.1111/j.1744-7429.2004.tb00353.x

[21] Romero, G.Q. and Vasconcellos-Neto, J. (2005) The Effects of Plant Structure on the Spatial and Microspatial Distribution of a Bromeliad-Living Jumping Spider (Salticidae). Journal of Animal Ecology, 74, 12-21.

https://doi.org/10.1111/j.1365-2656.2004.00893.x

[22] Thompson, J.N. (2005) The Geographic Mosaic of Coevolution. University of Chicago Press, Chicago. https://doi.org/10.7208/chicago/9780226118697.001.0001

[23] Medeiros, L.P., Garcia, G., Thompson, J.N. and Guimarães, P.R. (2018) The Geographic Mosaic of Coevolution in Mutualistic Networks. Proceedings of the National Academy of Sciences of the United States of America, 115, 12017-12022. https://doi.org/10.1073/pnas.1809088115 